\title{
Causal interpretation requires appropriate study design. Reply to Priest PC [letter]
}

\author{
S. J. Richardson • A. Willcox • A. J. Bone • \\ A. K. Foulis • N. G. Morgan
}

Received: 1 April 2009 / Accepted: 6 April 2009 /Published online: 29 April 2009

(C) Springer-Verlag 2009

Keywords Beta cells $\cdot$ Enterovirus $\cdot$ Environmental triggers $\cdot$ Insulitis $\cdot$ Islets of Langerhans $\cdot \mathrm{MHC} \cdot \mathrm{PKR}$. Type 1 diabetes $\cdot$ Type 2 diabetes

To the Editor: We fully agree with P. C. Priest [1] that the validity of controls is critical for the correct interpretation of the immunohistochemical data, and can confirm that careful attention was paid to this aspect of our study [2]. In particular, we would emphasise the following points.

First, the number of pancreas samples available from human patients who died shortly after receiving a diagnosis of type 1 diabetes is extremely small, and our collection represents by far the largest sample worldwide. As such, the samples constitute a unique resource for the analysis of the molecular pathology of type 1 diabetes in man. The pancreases used in the study were collected from autopsies carried out at a wide range of hospitals across the UK over a 25 year period dating from 1960, and the collection has previously been described in detail (for example, see [3]).

S. J. Richardson $\cdot$ A. Willcox $\cdot$ N. G. Morgan $(\bowtie)$

Institute of Biomedical and Clinical Sciences,

Peninsula Medical School, John Bull Building,

Tamar Science Park,

Plymouth PL6 8BU, UK

e-mail: noel.morgan@pms.ac.uk

\section{A. J. Bone}

School of Pharmacy and Biomolecular Sciences,

University of Brighton,

Moulescoomb,

Brighton, UK

\author{
A. K. Foulis \\ Department of Pathology, Royal Infirmary, \\ Glasgow, UK
}

Second, because of their varied origin, a non-uniform interval between death and post mortem, and variations in the methodology used to fix the specimens, it was necessary to select a wide range of non-diabetic groups to accommodate and control for these variables.

Third, the issue of neonatal controls is critically important and, contrary to the suggestion of P. C. Priest, this group is absolutely required for correct interpretation of the data. For immunohistochemical analysis, negative controls are at least as important as positive controls for determining the specificity of immunostaining (and we have employed both). Thus, we have been able to demonstrate that the islet cells of a group of neonates who were infected with culture-proven enterovirus stained positively for $\mathrm{vp} 1$ (thereby revealing that the virus has tropism for these cells in neonates). By contrast, the islets of a second group of neonates, who should not have encountered the virus, were uniformly negative. Hence, this provides important confirmation that the immunostaining pattern for vpl seen in the islets of human patients correlates with the expected pattern of infection. As a result, this helps to exclude the possibility that the antiserum was staining a non-viral antigen in the endocrine pancreas.

Fourth, as noted in our analysis, approximately $10 \%$ of control pancreases (spanning a wide range of ages) displayed some evidence of $\mathrm{vp} 1$ immunopositivity in the islet cells. This occurred at a much lower frequency (in terms of the proportion of infected beta cells) than was seen in patients with recent-onset type 1 diabetes, but, nevertheless, these results imply that enteroviral infection of beta cells is not uncommon in humans. As such, it is clear that the majority of such infections do not result in autoimmune diabetes. Rather, it appears that in a certain subgroup of 
susceptible individuals, enteroviral infection can initiate changes within the beta cells that ultimately provoke an autoimmune response. It is now important to characterise these changes in molecular terms in order to understand the role of persistent enteroviral infection in mediating beta cell-directed autoimmunity in such individuals.

Duality of interest The authors declare that there is no duality of interest associated with this manuscript.

\section{References}

1. Priest PC (2009) Causal interpretation requires appropriate study design. Diabetologia doi:10.1007/s00125-009-1346-3

2. Richardson SJ, Willcox A, Bone AJ, Foulis AK, Morgan NG (2009) The prevalence of enteroviral capsid protein vp1 immunostaining in pancreatic islets in human type 1 diabetes. Diabetologia doi:10.1007/s00125-009-1276-0

3. Foulis AK, Liddle CN, Farquharson MA et al (1986) The histopathology of the pancreas in type 1 (insulin-dependent) diabetes mellitus: a 25 -year review of deaths in patients under 20 years of age in the United Kingdom. Diabetologia 29:267-274 